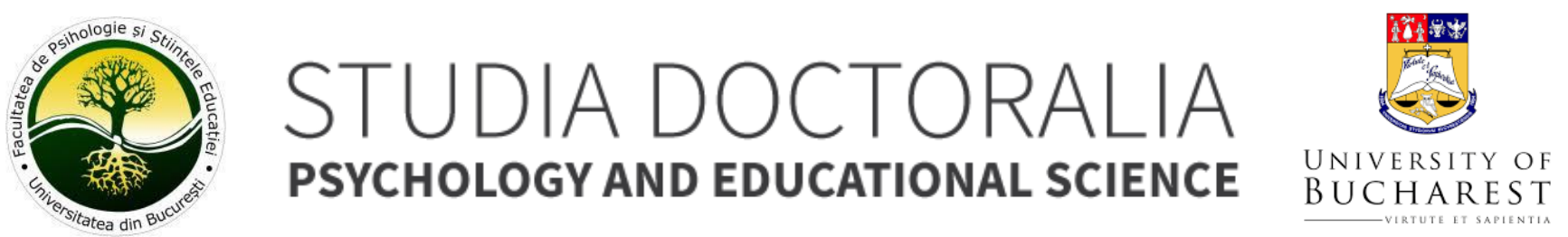

\title{
Effects of Negative Emotions on Cognitive Schemas
}

Marius-Gabriel Amzulescu, Andreea-lonela Chiscop, Diana-Nicol Marin, Cristina Lare, Andra-Maria Popescu

University of Bucharest

\section{ARTICLE INFO}

Article history:

Received 20-March-2020

Accepted 30-April-2020

Available online 01-May-2020

This article should be cited as: Amzulescu, M-G., Chiscop, A-I., Marin, D-N., Lare, C., Popescu, A-M. (2020). Effects of Negative Emotions on Cognitive Schemas. Studia Doctoralia. Psychology and Educational Science, 11(1), 6367.

This is an open access article under the CC BY license (http://creativecommons.org/licenses/by/4.0/).

Corresponding author at: University of Bucharest, Department of Psychology, 90 Panduri Av, Bucharest, RO. Tel.: +40 (0)728 767055 .

E-mail address:

marius-gabriel.m.amzulescu@s.fpse.unibuc.ro
ABSTRACT

The present study investigates the effect of negative emotions (focusing on disappointment, sadness and regret) on cognitive schemas. The sample consist in students from the University of Bucharest (convenience groups). A univariate unifactorial experimental design was used, as the current study had one independent variable, negative emotions, and a dependent variable, cognitive schemas, which was measured with the Core Beliefs Questionnaire instrument. We applied T test for independent samples, using SPSS. The $t$ test was statistically significant, $t(45)=$ $2.57, p<0.05$. The confidence interval $(95 \%)$ for the difference between the averages is between 2.95 and 24.35. After applying the intervention, the evaluated sample $(M=43.17, S D=29,074)$ showed a statistically significant difference compared to the control group $(M=29.52, S D=$ 11.257). The data collected support the main research hypothesis of the study, negative emotions can bring about changes in certain cognitive schemas by modifying, altering or disrupting them.

Keywords: negative emotions, cognitive schema, changes, disappointment, sadness, regret

\section{INTRODUCTION}

Cognitive patterns are central to Beck's cognitive model. Although schemas have been defined in a variety of ways, most definitions incorporate the idea that they consist of both structural (i.e., organizational) properties and propositional (i.e., content) elements (Ingram et al., 1998, cited in Dozois and Beck, 2008). Schmidt et al. (1999), for example, refer to schemas as "the basic structural components of the cognitive organization through which people identify, interpret, classify, and evaluate their experiences" (p. 129; see also Clark et al., 1999; James et al., 2007, cited in Dozois and Beck, 2008). This organized structure is often adaptive as it facilitates the speed with which people process information, thus requiring fewer controlled cognitive resources. However, well-organized internal representations of information are sometimes associated with a cost in which information can be selectively involved, 
encoded, and extracted in a way that is influenced by internal representation (e.g., when individuals are stereotyped based on ideas preconceived of an outgroup) (Linville, 1982, cited in Dozois and Beck, 2008).

Emotions and cognitions are by far among the most influential human mechanisms and currently occupy an important place both in neuroscience and clinique field. What we feel and think supports a mutual influence, in that it underpins our system of processing, integrating and performing various specific aspects of the environment, which will activate a wide range of equally specific cognitive, emotional, behavioral and psychobiological responses, according to the life situation to which an individual is exposed (David, 2015).

Emotion is an affective reaction, a psychic response of varying intensity, relatively short in duration, being accompanied by expressive, physiological, behavioral manifestations and has a situational character. Emotion mirrors the individual's attitude towards the reality in which he lives (Boncu \& Năstas, 2015).

Emotions play a very important functional role in an individual's life because they help us survive and adapt to complex and potentially dangerous physical and social situations. They represent our behavioral guide that activates and operates much faster than our ability to make conscious decisions (Larue et al., 2018). Instead, negative emotions such as shame, guilt, regret, disappointment and anger affect the way we perceive and relate to ourselves, others and the context, which in turn influence our thoughts and behaviors (Boncu \& Năstas, 2015).

Regarding cognitive schemas, these can be of two types. The first type describes irrational cognitions, meaning those cognitions which do not have a logical, empirical and pragmatic basis, functioning as vulnerability factor for various mental disorders. The most studied cognitions of this kind are: rigid thinking ( "I must necessarily..."), catastrophizing (when we evaluate a phenomenon as "the worst thing that could happen to us"), frustration intolerance (when we think that we cannot endures a certain situation) and the global assessment that takes place on three levels: 1) of one's own person ("I'm stupid" / "I'm unappreciated" etc.), 2) of other people ("It's stupid" / "It's unappreciated") and 3) of life ("Life is bad" / "Life is unfair"). The second type of cognitive schema is the rational one and this includes: flexible or preferential thinking (when we shape our desires or goals in flexible terms, not absolutist), which has three psychological components: preference, motivational intensity and acceptance. When we evaluate a phenomenon as something bad, not catastrophic we use our rational cognitive schema. Also it is found in frustation tolerence (when we think we can tolerate a certain situation, even if it is unpleasant) and unconditional acceptance of oneself ("I accept myself unconditionally; even if I have failed now, it means that my behavior needs to be improved, not that I'm stupid") or other people and life (unconditionally accepting certain people / situations even if we don't agree with them but instead their existence is accepted) (David, 2015).

It is known that there have been a wide range of theories affirming an existing structure regarding the relation between emotions and cognitions. Even if emotions are relevant variables in domains such as economy, management, medicine and decision-making models, these evaluate cognitive, situational and socio-cultural variables but the emotional component is rarely evaluated (Gutnik, Hakimzada, Yoskowitz \& Patel, 2006).

In 2018 a study was published which confirms an existing relation between negative emotions and cognitions, regarding working memory (Cavalera et al., 2018). A limitation of this study could be the fact that there were tested only two types of negative emotions: shame and guilt. Hence, it is desirable that future studies include more types of negative emotions, evaluating clinical and nonclinal samples. Ronnel and Elmer (2019) presented important implications for understanding implicit beliefs about emotions, emotional regulation and wellbeing. One of their findings states that the way people think about the flexibility of emotions may be an essential factor in emotional functioning.

There are several studies which operationalize and concentrate on the relation between state emotions and cognitions, including motivation, attention, attentional bias, cognitive bias, emotional congruence and personality traits or situational variables traits. Currently, from the theories of Easterbrook (1959, cited in Mandler, 1989) it is known that our attentional capacity to select and retain information is more and more impaired as the emotional intensity raises. Two concepts can be distinguished, the attentional narrowing moderated by positive affect and the one by negative affect.

In another relevant study, the influence of negative affects, particularly anxiety, on personal interpretation was operationalized. This study analyzed the verbal and nonverbal ambiguity that can be found in several activities, as well as the situational ambiguity and emotional expressions (Blanchette \& Richards, 2010).

Behavior and cognition are influenced by stable personality traits and emotional states. In a study, Hudlicka (2002) presents and operationalizes the effects of these variables that symbolically influence cognitive architecture. This approach starts with the hypothesis that the combined effects of these individual differences shape the architecture that is responsible for cognitive processing, but also for cognitive schemas. Studies in this field focus on what can be known (as processes), and less on personal cognitive schemas. Past research have not focused on all types of major negative emotions, such as sadness, disappointment, or regret in demonstrating an influence on cognitions. Thus, this paper intends to test a series of negative emotions to 
determine their role on cognitive schemas. Through this study we also wish to bring relevant information for future research in the field. Previous studies have shown limitations related to generalization issues, sample volume, or experimental methods used. The present research aims to investigate how emotions can modify, alter or disrupt certain cognitive schemas. The scientifical literature has long specified that emotions are the most malleable processes specifically human. It has long been known that certain musical stimuli (one of the most important functions of music being to change mood and emotional regulation) by duration alone (even less than a second of music is enough to denote emotional significance), the tone and intensity of an instrument or a voice can lead to certain emotional, behavioral and physiological reactions (DeNora, 1999; Juslin, Liljestrom, Vastfjall, Barradas, \& Silva, 2008; Sloboda, O'Neil, \& Ivaldi, 2001; Grewe, Nagel, Kopiez, \& Altenmuller, 2007b; Panksepp, 1995; Bigand, Vieillard, Madurell, Marozeau, \& Dacquet, 2005; Peretz, Blood, Penhune, \& Zatorre, 2001; Watt \& Ash, 1998, cited in Balteș, 2011).

There are two perspectives that want to explain the influence of music in terms of emotions. The first of these, called the emotivist position, admits that music can induce

\section{METHODOLOGY}

\section{Participants and procedure}

Participants were 66 students from Faculty of Psychology, Faculty of Law and Faculty of Business Management, University of Bucharest. The control group has 31 participants of which $64.5 \%$ are women and $35.5 \%$ men. The experimental group has 35 participants of which $62.9 \%$ are women and $37.1 \%$ are men. Using G-Power software, a posteriori, the given effect size was 0.5 and the power was 0.64 for a sample of 35 participants in the experimental group and 31 participants in the control group.

The procedure had at its core an online survey containing the measures described below, that the participants responded to. Also, the participants were informed concerning the nature and implications of the research and agreed by signing, using their first and last name, the informed consent from the online survey.

\section{Instruments}

\section{Core Beliefs Questionnaire}

The Core Beliefs Questionnaire (Wong et al., 2017) was used to measure the cognitive schemas of those who took part in this research, comprising a total of 17 items, including: "I am ridiculous", "I am incompetent", "I'm not worthy of anything." Participants raported if they agreed or disagreed with each statement, using a Likert scale from 1 emotions in listeners, and the second, that music can express emotions (this is called the cognitivist position) (Kivy, 1990; Scherer \& Zentner, 2001, cited in Balteș, 2011).

We expect, therefore, that this way of inducing emotions will be a suitable one for the present research and to explain the "why" that inevitably appeared in terms of explaining this phenomenon of inducing emotional states.

Thus, the main objective of the study is to capture the lack of verticality and functioning independently of psychoemotional and affective stimuli of precise cognitive schemas. This study brings in addition, the inclusion in the assessment of precise cognitive schemas that are related to the global evaluation of one's own person in an irrational way, as most studies refer to cognitions as complex and functional mechanisms. We consider relevant the choice of the research topic regarding the ecological validity that it can have, at least in the daily way of justifying and interpreting one's own activations of cognitive schemes, especially since little research has been carried out on the non-clinical population that emphasize these considerations.

The research hypothesis is formulated unilaterally by considering that experiencing a negative emotional state, through an emotional stimulus, will influence the current cognitive patterns.

(strongly disagree) to 6 (strong agreement). The tool was administered online through a Google Forms questionnaire.

\section{Design}

A univariate unifactorial experimental design was used, as the current study had a single independent variable, negative emotions, and a dependent variable, cognitive patterns. The negative emotions targeted in this study were disappointment, sadness, and regret, and the measured cognitive patterns were related to the overall assessment of one's self in an irrational manner.

The independent variable was manipulated directly, and so it was tried that the disappointment, sadness and regret be experimentally induced by listening to the song "Mad World", performed by Gary Jules. This song was chosen as a result of the decision of the researchers and not of any foundation derived from the scientific studies carried out on this topic. Only the experimental group listened this song. The control group didn't receive any intervention.

The total time for completing the questionnaire for a single topic was about 8 minutes, and regarding the data collection from all participants, the duration was two days.

Participation in this research was voluntary, and the data obtained from its conduct were strictly confidential. Also, the participants had the right and the possibility to withdraw at any time without further consequences. 


\section{RESULTS}

We applied the t test for independent samples, using the SPSS program, to calculate the difference between the averages of the two samples made up of the control group and the group that was intervened by inducing negative emotions, using a significance threshold $a=.05$. The dependent variable is represented by the cognitive schemes measured by means of the $\mathrm{CBQ}$ questionnaire (measured on interval / ratio scale), the independent variable was coded by means of the values $1=$ intervention and $2=$ control.

Following the application of the $t$ test for independent samples, we obtained two tables in the output area. Due to the fact that the value associated with the Levene test is less than 0.05 , we used the variance ratio and rejected the homogeneity of the variances, reading the result of the $t$ test on the second line of the table.

Table 1. Results of independent sample T-test, means and standard deviation

\begin{tabular}{llccccccc}
\hline & Negative_em & N & M & SD & t & df & $p$ & Cohen's d \\
\hline Core_beliefs & Intervention & 35 & 43.17 & 29.074 & 2.57 & 45.022 & .014 & .638 \\
& Control & 31 & 29.52 & 11.257 & & & & \\
& & & & & & & & \\
\hline
\end{tabular}

Note: Negative_em= negative emotions; Core_beliefs= Core Beliefs Questionnaire Score

The $\mathrm{t}$ test was statistically significant, $\mathrm{t}(45)=2.57, \mathrm{p}$ $<0.05, d=0.638$. The confidence interval $(95 \%)$ for the difference between the averages is between 2.95 and 24.35 . The sample evaluated in case of application of the

\section{DISCUSSION}

The negative emotions targeted were disappointment, sadness, and regret, and the measured cognitive schemas were related to the overall assessment of one's self in an irrational manner, which may mean that the way a person has self-knowledge is less stable in depending on the personality, and more variable depending on certain situational variables, intrinsic or extrinsic, which can generate negative emotions, whether they are adaptive or maladaptive. Thus, the way in which environmental factors or certain life experiences produce negative emotions, as well as the way in which certain events or situations are perceived without objective emotional valence, is a catalyst for changing self-perception, which at some point form vicious cause-and-effect circle.

This has a significant implication, suggesting that subtle changes in situational variables that generate positive emotions or reduce negative emotions can improve the quality of cognition about oneself. In the context of the scientific literature, the results of the research are in line with the results of the scientific community regarding this interaction of negative emotions and irrational cognitive schemas. This research confirm that personal interpretation is influenced by negative emotions (Blanchette \& Richards, 2010). Contextual differences shape the architecture that is responsible for cognitive processing, but also for cognitive schemas (Hudlicka, 2002). intervention ( $M=43.17, S D=29,074)$ showed a statistically significant difference compared to the group that was not intervened $(M=29.52, S D=11.257)$.

\section{Limitations}

This study has several limitations. Because of the small sample size, it is possible that the experimental group had participants with an irrational global self-evaluation. The experimental group could have negatively perceived the goal of the study and the desirability of the answers, which would have determined them to "conform" with the "right" answer. Also, those from the experimental group may have responded based on the way they evaluate themselves when feeling emotions which are consistent with the song used as independent variable, but this fact is not equivalent with their global cognitions.

\section{Future directions of study and implications}

Future study directions consist in analyzing a baseline of participants, to see if there is a correlation between certain personality traits, such as neuroticism, anxiety, low selfesteem, psychological well-being, life satisfaction, extraversion , and irrational cognitive schemas. When this correlation exists, it means that the results are due to this correlation and not due to the induction of negative emotions.

Another important future direction of study is to perform the experiment, using different groups, functional and dysfunctional, to induce negative emotions. 
The theoretical implications of this research lead to future hypotheses, such as those mentioned above, using better control of confused variables.

The practical implications of this research are social, as the fact that negative emotions can temporarily change cognitive patterns on oneself in an irrational way, are facts that can be used in psychopedagogy, psychology and school counseling. If a student has an irrational and dysfunctional global self-assessment, this can be changed much more easily by monitoring the negative emotions to which he is exposed, for example the way he is treated by teachers or colleagues. Thus, we can look more closely at how a person can perceive himself in an irrational way, without considering the preconceived notion that this is a stable part of his personality. This applicability is also

\section{REFERENCES}

Balteș, F. R. (2011). Emoțiile induse de muzică: Corelate psihofiziologice și diferențe interindividuale (Teză de doctorat nepublicată). Universitatea Babeș-Bolyai, ClujNapoca, România.

Blanchette, I., \& Richards, A. (2010). The influence of affect on higher level cognition: $A$ review of research on interpretation, judgement, decision making and reasoning. Cognition and Emotion Reviews of Current Research and Theories, 276-324.

Boncu, S., \& Năstas, D. (2015). Emoțiile complexe. Iași: Polirom.

Cavalera,C., Pepe, A., Zurloni, V., Diana, B., Realdon, O., Todisco, P., Castelnuovo, G., Molinari, E., \& Pagnini, F. (2018). Negative social emotions and cognition: Shame, guilt and working memory impairments. Acta Psychologica, 188, 9-15.

David, D. (2015). Psihologia poporului român. Profilul psihologic al românilor într-o monografie cognitivexperimentală. Iași: Polirom. functional in organizational psychology, when employees behave more unproductively or having a lack of motivation.

\section{Conclusions}

In accordance with the objective of the study presented at the beginning of the paper, negative emotions as a state can bring changes in cognitive patterns by modifying, altering or disrupting them. Thus, the unilaterally formulated research hypothesis is supported by statistical data, which reveals that experiencing a negative emotional state, through an emotional stimulus, influences current cognitive patterns. The applicability of this research has also been demonstrated through sections dedicated to future discussions and directions that can open new perspectives and aspects that can be taken into account in future research that are meant to address this topic.

Dozois, D., \& Beck, A. T. (2008). Cognitive Schemas, Beliefs and Assumptions. Risk Factors in Depression, 119-143.

Gutnik, L. A., Hakimzada, A. F., Yoskowitz, N. A., \& Patel, V. L. (2006). The role of emotion in decision-making: A cognitive neuroeconomic approach towards understanding sexual risk behavior. Journal of Biomedical Informatics, 39(6), 720-736.

Hudlicka, E. (2002). This time with feeling: Integrated model of trait and state effects on cognition and behavior. Applied Artificial Intelligence, 16(7-8), 611-641.

Larue, O., West, R., Rosenbloom, P. S., Dancy, C. L., Samsonovich, A. V., Petters, D., \& Juvina, I. (2018). Emotion in the Common Model of Cognition. Procedia Computer Science, 145, 740-746.

Ronnel, B. K., \& Elmer, D. (2019). Are your emotions under your control or not? Implicit theories of emotion predict wellbeing via cognitive reappraisal. Personality and Individual Differences, 138, 177-182. 